\title{
Comparison of Early Maladaptive Schema of Adult Children of Schizophrenic Parent With Adult Children crossuark of Healthy Parent
}

\author{
Delaram Salehi $^{{ }^{*}}$, Ali Reza Abedin ${ }^{1}$, Mohamad Reza Tavakoli Hassan Abadi ${ }^{1}$ \\ 1. Department of Psychology, Faculty of Humanities and Social Sciences, Science and Research Branch, Islamic Azad University, Tehran, Iran.
}

\begin{tabular}{|l|l|}
\hline $\begin{array}{c}\text { Use your device to scan } \\
\text { and read the article online }\end{array}$ & $\begin{array}{l}\text { Chtation: Salehi, D., Abedin, A. R., Tavakoli Hassan Abadi, M. R. (2016). Comparison of Early Maladaptive Schema of Adult } \\
\text { Children of Schizophrenic Parent With Adult Children of Healthy Parent. Journal of Practice in Clinical Psychology, 5(1), 3-10. } \\
\text { https://doi.org/10.18869/acadpub.jpcp.5.1.3 }\end{array}$ \\
dof: $:$ https://doi.org/10.18869/acadpub.jpcp.5.1.3
\end{tabular}

Article info:

Received: 31 Aug. 3016

Accepted: 01 Dec. 2016

Keywords:

A parent with schizophrenia, Children, Early maladaptive schemas

\begin{abstract}
Objective: This project aimed to study early maladaptive schemas in adults with parents afflicted with schizophrenia.

Methods: In a causal-comparative study, a sample of 39 adults with one schizophrenic parent as the experiment group and 40 students without schizophrenic parents as the control group were selected. Both groups completed early maladaptive schema questionnaire. Descriptive statistics as well as multi-and single-variable analysis of variance were applied.

Results: Significant differences were found in early maladaptive schemas of rejection/ disconnection, impaired autonomy/performance, and over vigilance/inhibitions as well as in the subscales of emotional deprivation, defectiveness/shame, failure, and unrelenting standards.

Conclusion: Feelings of failure and insecurity leads to formation of early maladaptive schemas in children of schizophrenia. The chronicity of schizophrenia, patients' behavioral difficulties, and stigmatization lead to feelings of defectiveness and lack of security in children and early maladaptive schemas.
\end{abstract}

\section{Introduction}

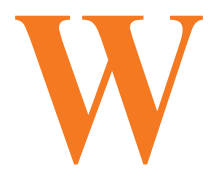

hen parents suffer from severe psychosis, their children who need dedication, security, and emotional support also suffer (Rohrbaugh, 2008). Schizophrenia is a debilitating mental disease, and one of the top ten causes of long-term disabilities. It affects the people's social, economic, and intellectual productivity (Balada et al., 2015). People with schizophrenia are strongly involved in their eccentric inner thoughts and perceptions, as if they do not live in this world. This condition can put more pressure on the patient's family and caregivers (Lotfi, 2007). On the other hand, unawareness of the disease is seen in the people with schizophrenia indicating problems in evaluating themselves. When patients do not believe in their sickness, they refuse treatments which worsens the disease and creates numerous difficulties in patients' daily performance, cognition, and attitude (Phillip \& Pinkham, 2015). In addition, being stigmatized as a mental patient is an important and stressful factor which its most severe

* Corresponding Author:

Delaram Salehi, $M A$

Address: Department of Psychology, Faculty of Humanities and Social Sciences, Science and Research Branch, Islamic Azad University, Tehran, Iran. Tel: +98 (912) 6498368

E-mail: delaram.salehi@yahoo.com 
effects are reduction of self-confidence in the members of the families and damage to their relationships (Sadeghi, Kaviani, \& Rezaei, 2003). Particularly children more than the other family members are under pressure due to communication with their sick parents.

However, the studies, which have been already conducted, were not helpful in revealing the depth and complexity of the experiences of children lived with parents with mental disease (Loshak, 2013). One of the adverse effects of the schizophrenic parent, father or mother, is the increased risk of suicide in their children and the continuity of the risk in adulthood. These findings demand more attention to the children of the parents with schizophrenia and their thoughts (Ljung et al., 2013). On this basis, detailed study on the psychological dimensions of adult children of parents with schizophrenia is important. High vulnerability in these children can be due to combination of genetic, psychological, and social factors. Children with psychotic parents, in particular, inherit the genetic disorder and are exposed to the effects of the disease, as long as their psychotic parents live with them at home (Preston \& Antin, 1932).

Mothers with mental disease have poor parenting skills. They are emotionally less available and develop weak positive relationships with their children (Herbert, Menjula, \& Merima, 2012). In addition, they have less tactful and efficient interaction with their children (Wan, Moulton, \& Abel, 2008). A mother who lacks proper accountability and stimulation, loses vitality and freshness (Kohut, 1977). Parenting skills and methods that parents apply in dealing with their children have considerable influence on forming children's cognitive skills and cognitive organizations called schema (Makvand Hosseini, Rezaei, \& Ezzeddin, 2014).

Early maladaptive schema are formed as fixed cognitive-affective models during the early human development and on the basis of patient's interpersonal relationships. These schema are repeated as a reflection of the human's life (Yang, Bae, \& Lee, 2012). On the other hand, when parents suffer from a mental disease, physical and emotional care of their children will be affected. Consequently, the children are more likely to have unpleasant experiences (Herbert et al., 2012). The emotional and affective needs of children of the parents with schizophrenia are not met due to undesirable parenting they receive within the family. The early maladaptive schema are created because basic emotional needs in childhood are not satisfied. Such needs include secure attachment to others, autonomy, competence, identity and normal emotions of spontaneity and entertainment, realistic limitations, and self-control. Young presented 18 schema based on 5 main emotional needs and called them schema domains (Young,1994).

First domain is disconnection and rejection, including the schema of abandonment, mistrust, emotional deprivation, defectiveness, and social isolation. Second domain is impaired autonomy and performance, including the schema of incompetence, undeveloped self, vulnerability to harm, and failure. Third domain is impaired limits, including entitlement and insufficient self-control. Fourth domain is other-directedness, including the schema of subjugation, self-sacrifice, and approval-seeking. Fifth domain is over-vigilance, including the schema of negativity/pessimism, emotional inhibition, unrelenting standards, and punitiveness (Young,1994).

The present research examined the development of early maladaptive schema in children whose father or mother has schizophrenia. So far, many studies conducted on the children of a parent with schizophrenia have mainly focused on the risk of suffering from different mental disorders and behavioral problems of these children. However, insufficient attention has been paid to the children of schizophrenic parents with no clinical diagnosis while these children have had the experience of living with their sick parents (Menjula \& Regiurm, 2009). In some families, caregivers are put under anger attacks and verbal abuse of the patient. These problems endanger the health of the family members (Lotfi, 2007). The long-lasting and devastating effects of a person with mental disorder in a family are evident. The objective of the research was to examine the effects of a parent with schizophrenia, as one of the severe mental illnesses, in developing early maladaptive schema in their children. In this regard, the research hypothesis is "there is a relationship between having a parent with schizophrenia and developing early maladaptive schema in their children."

\section{Methods}

The present research is a fundamental study. The research design was cross sectional. Study population comprised adult children ( $>18$ years old) of the families in which one of the parents was affected by schizophrenia.

A total of 39 subjects between the ages of 18 and 36 took part in this study. In this research, convenient sampling method was used (Table 1). The researchers referred to the mental health centers like psychiatric hospitals, the department of social welfare of Qazvin Province, and Iranian Society for the Protection of Schizophrenic Patients. At these centers, the psychiatric files 
were reviewed. In the schizophrenic cases with children over 18 years old, the families were contacted and upon their willingness to take part in the study, consent forms along with study questionnaires were sent to the children to be signed and completed.

Students from different parts of the country with different ethnic backgrounds and levels of mental health in their families attend Iran universities. Hence they may be considered as an appropriate control group for this project. Forty students whose parents were not affected by schizophrenia were considered as the control group. The control group was selected by convenient sampling method. Participants in both groups were in the same age range. Lack of parents' mental illness in the control group was established via a researcher made demographic questionnaire comprising questions about general information such as age, gender, etc. as well as mental health status of their parents. To analyze the obtained data, descriptive statistics and univariate and multivariate analysis of variance were applied.

Individual characteristics questionnaire collects demographic information of the subjects. This questionnaire assesses the subjects' ages, time of parents' psychiatric diagnosis, and the number and duration of parents' hospitalization.

Young's schema questionnaire-short form (YSQ-SF) has been designed to evaluate early maladaptive schema (EMS) (Young \& Brown, 1994; Cited in Ahi, Mohamadi Far, \& Besharat, 2007). This questionnaire includes 75 items. The items measure 15 maladaptive schema in 5 domains (Rafiei, Hatami, \& Forooghi, 2011). They are scored on a 6-point scale (absolutely true: 6, mostly true: 5 , almost true: 4 , more true: 3 , false: 2 , absolutely false: 1). High scores indicate the existence of early maladaptive schema (Ahi et al., 2007). The reliability of the questionnaire has been found between 0.76 and 0.93 for all schema by using the Cronbach $\alpha$ (Welbern et al., 2002). The results of factor analysis also support the internal consistency of the questionnaire. Fatehizadeh and Abbasian (2003) also calculated its reliability as 0.94 by using the Cronbach $\alpha$ method and its validity as 0.34 by Irrational Believes Test (IBT) (Ahi et al., 2007).

\section{Results}

To examine the difference between two groups and its relationship to development of early maladaptive sche$\mathrm{ma}$ in children, the multivariate analysis of variance test was used. Wilks lambda was set at 0.005 .

The findings of the multivariate analysis of variance test showed that the difference between two groups was significant at the significance level of $\mathrm{P}=0.005$. When the difference became significant at the general level, the difference at subscales was examined. To this end, the univariate analysis of variance test was used (Table 2).

The results of the multivariate analysis of variance in 5 domains of early maladaptive schema between two groups indicated that the domains of rejection/abandonment $(\mathrm{P}=0.29)$, autonomy/impaired performance $(\mathrm{P}=$ 0.25 ), and over-vigilance/inhibition had significant differences (Table 3). Then, to evaluate the hypothesis of the research, 15 subscales of early maladaptive schema were examined separately in two groups, using the multivariate analysis of variance (Table 3).

The results of the multivariate analysis of variance indicated that the difference was significant $(P=0.010)$. When the difference became significant at the general level, the difference at the level of the subscales were examined. To this end, the univariate analysis of variance was used (Table 4).

The results of the univariate analysis of variance in 15 early maladaptive schema indicated significant difference between two groups with regard to the schema of defectiveness/shame $(\mathrm{P}=0.031)$, failure $(\mathrm{P}=0.032)$,

Table 1. The descriptive findings of maladaptive schema in two groups

\begin{tabular}{cccccc}
\hline & Frequency & Least & Most & Mean & The Standard Deviation \\
\hline Rejection/Abandonment & 78 & 5.80 & 24.35 & 12.7314 & 4.44901 \\
Autonomy/Impaired performance & 78 & 5 & 20.75 & 10.4575 & 15.4545 \\
Impaired limits & 76 & 5.50 & 27.50 & 29 & 15.1474 \\
Other-directedness & 78 & 7.25 & 82 & 16.3670 & 5.67684 \\
Over-vigilance & 75 & 6 & & 5.36634 \\
\hline
\end{tabular}


Table 2. The univariate analysis of variance to compare 5 domains of maladaptive schema in two groups

\begin{tabular}{|c|c|c|c|}
\hline Source of Variance & Dependent Variable & $\mathbf{F}$ & Significance \\
\hline & Rejection/Abandonment & 4.951 & 0.029 \\
\hline & Autonomy/Impaired performance & 5.231 & 0.025 \\
\hline \multirow[t]{3}{*}{ Group } & Impaired limits & 342 & 0.560 \\
\hline & Other-directedness & 370 & 0.546 \\
\hline & Over-vigilance & 4.43 & 0.039 \\
\hline
\end{tabular}

Table 3. Multivariate analysis of variance to compare 15 early maladaptive schema in two groups

\begin{tabular}{|c|c|c|c|c|c|}
\hline Indicator & Value & $\mathbf{F}$ & Hypothesis df & Error df & Significance \\
\hline Pillai's trace & 0.369 & 2.344 & 15 & 60 & 0.010 \\
\hline Wilk's lambda & 0.631 & 2.344 & 15 & 60 & 0.010 \\
\hline Hotelling's trace & 0.586 & 2.344 & 15 & 60 & 0.010 \\
\hline Roy's largest root & 0.586 & 2.344 & 15 & 60 & 0.010 \\
\hline
\end{tabular}

Table 4. The univariate analysis of variance to compare 15 early maladaptive schema in two groups

\begin{tabular}{|c|c|c|c|}
\hline Source of Variance & Dependent Variable & $\mathbf{F}$ & Significance \\
\hline & Emotional deprivation & 16.742 & 0.000 \\
\hline & Abandonment & 1.882 & 0.174 \\
\hline & Mistrust & 0.766 & 0.384 \\
\hline & Social isolation & 2.121 & 0.150 \\
\hline & Defectiveness/Shame & 4.822 & 0.031 \\
\hline & Failure & 4.789 & 0.032 \\
\hline & Dependency/Incompetence & 2.730 & 0.103 \\
\hline \multirow[t]{8}{*}{ Group } & Vulnerability to harm & 2.087 & 0.153 \\
\hline & Caught & 3.235 & 0.079 \\
\hline & Subjugation & 1.285 & 0.261 \\
\hline & Self-sacrifice & 0.001 & 0.970 \\
\hline & Emotional inhibition & 2.559 & 0.114 \\
\hline & Unrelenting standards & 4.123 & 0.046 \\
\hline & Entitlement & 0.748 & 0.390 \\
\hline & Insufficient self-discipline & 0.018 & 0.890 \\
\hline
\end{tabular}


emotional deprivation $(\mathrm{P}=0.000)$, and unrelenting standards $(\mathrm{P}=0.046)($ Table 4$)$.

\section{Discussion}

According to the study findings, the research hypothesis was confirmed i.e., there was a significant relationship between developing early maladaptive schema in the children and suffering from having one parent affected with schizophrenia in the family. Parents influence their children's social development through providing a suitable environment and supervising on their social activities. When one of the parents suffers from a mental disease, his or her incompetence and discomfort caused by the illness disturbs their family environment (Hashemian, 1992). If family loses its balance, it will turn into a morbid world (Tajik Esmaeili, 1991). In this regard, early maladaptive schema of the children of parents with mental illness are a reflection of their horrible environment, the environment in which the children's needs for dedication, security, and emotional support are not met (Rohrbaugh, 2008); The basic needs that failure to satisfy them will result in development of the schema of rejection domain.

Confirmed by the present research, the rejection domain, which causes the most psychic trauma (Akbari et al., 2012), is significant among the children having a parent with schizophrenia. Likewise, mothers with schizophrenia have the lowest quality of parenting compared to depressed and normal mothers (Goodman \& Brumley, 1990). Maladaptive schema are also as a perception catalyzer of parenting behaviors and symptoms of personality disorders (Thimma, 2010). Obviously, having a parent with schizophrenia forms such beliefs in their children which are characteristics of the rejection domain. A domain of schema which often indicates inconstant, cold, misbehaving, and repercussive families (Renner, Lobbestael, Peeters, \& Arntz, 2012).

Our study results indicated the maladaptive schema of emotional deprivation and defectiveness/shame, which are among the most injurious and powerful of the four schema domain of rejection, had the highest level of significance. These schema arise because of unpleasant satisfaction of needs and experiences such as being injured and sacrificed (Akbari et al., 2012). Severe mental diseases can cripple parents to do even simple tasks such as feeding and taking care of their children (Hashemian, 1992). It also affects their physical and emotional cares and increases the possibility of unpleasant experiences in their children (Herbert et al., 2012).
Children who have not received sufficient physical and affective cares in their own family, in other words, have been forgotten and rejected, most probably will suffer from the schema of emotional deprivation. They have not been satisfied with their desires and needs for emotional support in the format of intimate relationship with others, and as a result, they have little confidence and trust in themselves (Razavi, Fatehizadeh, Etemadi, \& Abedi, 2010).

People with the schema of defectiveness/shame feel shameful about perceived defectiveness and believe in being rejected by others (Akbari et al., 2012). With regard to this schema in these children, it can be noted that many families who have patients with schizophrenia are discriminated and ridiculed. Clearly, one of the consequences of being stigmatized is a sense of shame in the family members (Sadeghi et al., 2003). Also, many patients with schizophrenia belongs to low-income and middle-income classes of the society. In the family, these patients are not sources of income, but consume financial resources, consequently, a schizophrenic patient will further push families into poverty (Lotfi, 2007). Obviously, living under these unpleasant conditions and clinical situation of parents with schizophrenia affect self-esteem of their children. As a result, these children have poorer self-concept compared to the children of healthy parents (Manjula \& Raguram, 2009). Based on the characteristics of this schema, these persons consider themselves worthless and unwanted.

Second category of early maladaptive schema, which is prevalent among the children having parents with schizophrenia, is the domain of autonomy/impaired performance. These parents are unable to encourage children's independent performance in the society and lead to their children's low self-confidence (Akbari et al., 2012). Of four schema related to this domain, the schema of failure is prominent among children with schizophrenic parents. People with this schema consider themselves incompetent and unsuccessful compared to their peers.

This incompetency is due to defective parenting. Parents rear social aspect of their children through parentchild interaction such as imitation, identification, and learning emotional expressions. They influence their children's social development through providing a suitable environment and supervising on their activities. However, if the parents suffer from a trauma, they will be inattentive to proper education of their children. They are impatient, preoccupied by the disease, and possible hospitalization. Obviously, there will be dramatic changes in educational efforts of the sick parents, which prevents the creation of a suitable environment for their 
children's social growth. Consequently, the possibility of disorder in the domains of autonomy and their performance is expected (Hashemian, 1992).

Third category of early maladaptive schema, which is significant among children having parents with schizophrenia, is the domain of over-vigilance. People with this domain, have had a childhood full of violence and crackdown, and over self-control has been preferred on spontaneity and pleasure. These people are vigilance over all negative events of life. They think that if they are not careful enough, their life will collapse. Of schema of this domain, the unrelenting standards/extreme reproach schema is significant among children having parent with schizophrenia. This schema leads to the disorder in valuable sensation, interpersonal relationships, or defective enjoyment of life (Akbari et al., 2012).

To explain the above findings, it can be argued that there are a lot of pressure and anxiety in the families with schizophrenic patient; particularly children feel this pressure. Furthermore, schizophrenia is the most common and severe mental disorder, which affects all aspects of a person's life (Sobhani, Moradi, Alibeygi, \& Dolatshahi, 2010). The family should hospitalize the patient many times. In Iran, such patients are hospitalized more than three times and the longest hospitalization time is three months. In addition, schizophrenia is the most costly mental disorder directly due to costs of treatment and indirectly through unemployment of the patient (Lotfi, 2007). Besides high costs of the treatment, the family members are also subjected to stigma of the illness and its limitation (Bakhtiari, 2008).

Therefore, the children of these families develop the schema of over-vigilance. They probably always pay close attention to their surroundings to notice the symptoms of their parents, behavioral disorders, and financial need of the family (Lotfi, 2007). Roles and responsibilities of family members of these patients change which lead to derangement and confusion (Lotfi, 2007). Consequently, these children do not probably have much time for recreation and joy, and instead, think about the occurrence of negative events which is one of the features of the stigma schema domain. Furthermore, developing the schema of unrelenting standards, including perfect integration, time concerns, and efficiency (Akbari et al., 2012) is natural for these persons who should always pay attention to family environment and exact fulfillment of the responsibilities.

In addition, behavioral disorders of the patient and stigma of the illness the family members incur lead to more limitation in their social relationships. This in turn, ends in more loneliness and loss of support (Lotfi, $2007-$ 2008). Such experiences lead to the development of pessimism and fear of collapsing life which are seen in the schema of over-vigilance.

According to what was discussed, the long-lasting and devastating effect of having a person with mental illness in the family is evident. However, few studies have been conducted on the experiences of a child grown up in an environment saturated with stress and pressure with regard to a parent with serious illness of schizophrenia. It is hoped that this research serves as a step towards identifying the cognitive dimensions of these children and thereby aid to develop supporting programs and appropriate treatment plans for them. The study limitation is its small sample size, which limits generalization of the results.

One of the major reasons for the small sample was unwillingness of some children to be reminded of their past and the times they felt powerless in facing this illness; thus many children did not respond to the study questionnaires. Moreover, the diagnoses in the study patients' psychiatric files, did not specify types of schizophrenia with positive or negative symptoms. As a result, the effects of positive and negative symptoms of schizophrenia on the formation of the psychological dimensions of children were not studied. In the future studies, it is recommended that in addition to resolving the limitations mentioned above, projective tests be used to assess the children's inner world more deeply. This may also reduce the chance of bias in the answers they provide. Additionally, assessing the effect of parents with schizophrenia on other variables such as anger management, coping strategies, and so on in their children may help in further identification of these children's needs.

\section{Acknowledgements}

This article was extracted from the MA thesis of the first author and had no financial sponsors.

\section{Conflict of Interest}

The authors declared no conflict of interests. 


\section{References}

Ahi, Gh. (2007). [Reliability and validity of Young's schema Questionnaire-Short Form (Persian)]. Journal of Psychology $\mathcal{E}$ Educational Sciences, 37(3), 5-20.

Akbari, A., Aliloo, M. M., Khanjani, Z., Poorsharifi, H., Fahimi, S., Pichakolaei, A., et al. (2012). [Comparison of students having love failure with and without clinical symptoms in early maladapted schema and parenting patterns (Persian)]. Journal of Iranian Psychiatry \& Clinical Psychology, 18(3), 184-194.

Bakhtiari, R. (2008). [Emotional Intelligence of children having parents with Schizophrenia and children having parents with depression and developing and applying emotional intelligence training program in the children having parents with Schizophrenia (Persian)] (MA thesis). Tehran: Shahid Beheshti University.

Balada, M., Calvo, M., Padilla, E., Guerrero, G., Molina, J., Florenzano, V., et al. (2015). Detection, assessment and management of schizophrenia in an Andean population of South America: Parkinsonism testing and transcranial ultrasound as preventive tools. Focous, 13(4), 432-40. doi: 10.1176/appi. focus. 20150018

Bell, M. D. (1995). Bell Object Relations and Reality Testing (BORRTI) Manual. Los Angles: Western Psychological.

Bell, M. D., Billington, R., \& Becker, B. (1986). A scale for the assessment of object relation: Reliability, validity, and factorial invariance. Journal of Clinical Psychology, 42(5), 733-41. doi: 10.1002/1097-4679(198609)42:5<733::aidjclp2270420509>3.0.co;2-c

D'Angelo, E. J. (1986). Security of attachment in infants with schizophrenic, depressed, and unaffected mothers. Journal of Genetic Psychology, 147(3), 421-22. doi: 10.1080/00221325.1986.9914517

Goodman, S. H., \& Brumley, H. E. (1990). Schizophrenic and depressed mothers: Relational deficits in parenting. Developmental Psychology, 26(1), 31-39. doi: 10.1037//0012-1649.26.1.31

Haghighatmanesh, A., Agha Mohammadian Sherbaf, H., Ghanbari Hashemabadi, B. A., \& Mahram, B. (2010). [Early Maladaptive Schemas and Schema Domains in Rapists (Persian)]. Iranian Journal of Psychiatry and Clinical Psychology, 16(2), 145-53.

Haprich, S. K. \& Greenberg, R. P. (2003). Advance in the assessment of object relations in the 1990s. Clinical Psychology Review, 23(5), 665-98. doi: 10.1016/s0272-7358(03)00072-2

Hashemian, K. (1992). [Influence of depressed mothers on psychological development of their children (Persian)]. Journal of Science (Al-Zahra University), (9-10), 69-81.

Hasnson, J. W. (2002). Review of empirical research that utilized the bell object relation inventory ( $\mathrm{PhD}$ thesis). California: Biola University.

Herbert, H. S., Manjula, M., \& Philip, M. (2012). Resilience and factors contributing to resilience among the offsprings of parents with schizophrenia. Psychology Studies, 58(1), 80-88. doi: $10.1007 /$ s12646-012-0168-4

Jafari, A., Pooyamanesh, J., Ghorbanian, N., \& Kabiri, M. (2013). [The effectiveness of schema therapy on moderating early maladaptive schemas and reducing students' anxiety sensitivity (Persian)]. Instruction \& Evaluation, 6(24), 79-91.
Klein, M. (1975). The mutual influences in the development of ego and id. In envy and gratitude and another works. New York: Delta Books.

Kohut, H. (1977). The restoration of the self. New York: International University Press.

Ljung, T., Linchtenstein, P., Sandina, S., D'onofrio, B. Runeson, B., Lagstrom, N., et al. (2013). Parental schizophrenia and increased offspring suicide risk: Exploring the casual hypothesis using cousin compression. Psychological Medicine, 43(3), 581-90. doi: $10.1017 /$ s0033291712001365

Loshak, R. (2013). Living with a parent with mental health needs, out of mainstream: Helping the children of parents with a mental illness. London: Routledge Publication.

Lotfi, M. (2007). [Effectiveness of group cognitive-behavioral interventions on mental health promotion of families having patients with Schizophrenia (Persian)] [MSc. thesis]. Tehran: Tehran University of Medical Sciences.

Makvand-Hosseini, Sh., Rezaei, A., \& Ezzeddin, M. (2014). [Effectiveness of schema-focused cognitive group therapy on early maladaptive schema of homeless and difficult parents adolescents (Persian)]. Journal of Clinical Psychology, 6(2), 8398.

Manjula, M., \& Raguram, A. (2009). Self-concept in adult children of schizophrenic parents: An exploratory study. In ternational Journal of Social Psychiatry, 55(5), 471-79. doi: $10.1177 / 0020764008094732$

Philip, D., \& Pinkham, A. (2015). Impaired self-assessment in schizophrenia: why patients misjudge their cognition and functioning observation from caregivers and clinicians seem to have the most validity. Current Psychiatry, 14(4), 53-59.

Preston, G., \& Antin, R. (1932). A study of children of psychotic parents. American Journal of Orthopsychiatry, 2(3), 231-41. doi: 10.1111/j.1939-0025.1932.tb05181.x

Rafiee, S., Hatami, A., \& Foroughi, A. (2011). [The relationship between early maladapted schema and attachment style in women having Infidelity (Persian)]. Sociology of Women (Journal of Woman and Society), 2(1), 21-36.

Razavi, A. S., Fatehizadeh, M. S., Etemadi, A., \& Abedi, M., R (2010). [Determining the relationship of early maladapted schema with the dimensions of attitude to select spouse in students of Payam-e-Noor University of Tehran Province (Persian)]. Counseling Culture and Psychotherapy, 1(2), 45-70.

Renner, F., Lobbestael, J., Peeters, F., \& Arntz, A. (2012). Early maladaptive schema in depressed patients: Stability and relation with depressive symptoms over the course of treatment. Journal of Affective Disorder, 136(3), 581-90. doi: 10.1016/j jad.2011.10.027

Riordan, D., Appleby, L., \& Faragher, B. (1999). Mother-infant interaction in post-partum women with schizophrenia and affective disorder. Psychological Medicine, 29(4), 991-95. doi: 10.1017/s0033291798007727

Rohrbaugh, J. B. (2008). A comprehensive guide to child custody evaluation: Mental health and legal perspective. New York: Springer.

Ross, G., \& Compagnon, N. (2001). The diagnosis and treatment of psychotic disorders in children with a schizophrenic parent. Schizophrenia Research, 5(1-2), 121-26. doi: 10.1016/s09209964(00)00043-8 
Sadeghi, M., Kaviani, H., \& Rezaei, R. (2003). [Comparative examination of mental disease stigma in families having patients with depression disorder, bipolar disorder, and Schizophrenia (Persian)]. Advances in Cognitive Science, 5(2), 16-25.

Simard, V., Moss, E., \& Pascuzzo, K. (2011). Early maladaptive schema and child and adult attachment: A 15-year longitudinal study. British Psychological Society, 84(4), 349-66. doi: 10.1111/j.2044-8341.2010.02009.x

Sobhani, M., Moradi, A., Alibeygi, N., \& Dolatshahi, B. (2010). [Effectiveness of cognitive-behavioral treatment in reducing symptoms and performance improvement of patients with Schizophrenia (Persian)]. Clinical Psychology Studies, 1(1), 10128.

Tajik Esmaeili, A. (1991). [Family and its role in developing behavioral disorders (Persian)]. Tarbiat, 6(9), 5-9.

Thimma, J. C. (2010). Mediation of early maladaptive schema between perceptions of parental rearing style and personality disorder symptoms. Journal of Behavior Therapy and Experimental Psychiatry, 41(1), 52-59. doi: 10.1016/j.jbtep.2009.10.001

Trad, P. V. (1986). Infant depression, paradigms and paradoxes. New York: Springer.

Wan, M., \& Green, J. (2009). The impact of maternal psychopathology on child-mother attachment. Archives of Women's Mental Health, 12(3), 123-34. doi: 10.1007/s00737-009-0066-5

Wan, M., Moulton, S., \& Abel, M. (2008). A review of motherchild relational interventions and their usefulness for mothers with schizophrenia. Archives of Women's Mental Health, 11(3), 171-79. doi: 10.1007/s00737-008-0010-0

Welburn, K., Coristire, M., Daggy, P., Pontefrad, A., \& Jordan, S. H. (2002). The schema questionnaire short form: Factor analysis and relationship between schema and symptoms. Cognitive Therapy and Research, 26(4), 519-30.

Yang, D. S., Bae, G. Y., \& Lee, S. J. (2012). Stability of early maladaptive schema and their relationship with depressive symptoms: A 2-year follows up study. Journal of Korean Neuro Psychiatric Association, 51(4), 156-63. doi: 10.4306/jknpa.2012.51.4.156

Young, J. E. (1994). Cognitive therapy for personality disorders: A schema-focused approach. Sarasota: Professional Resource Exchange. 